\title{
A RELIABLE, VERSATILE SYSTEM FOR ASSESSING OXYGEN INTAKE
}

\author{
J. L. MAYHEW, B.Sc., M.Sc.
}

Department of Physical Education, University of Illinois, Champaign, Illinois

As metabolic analysis under the stress of exercise expands its horizons beyond the assessment of maximal oxygen intake, a more versatile system than the cumbersome Douglas bag apparatus is warranted. With the advent of continuous observation of energy demands of submaximal work over extended periods (Costill, Kammer, and Fisher, 1970; Costill et al., 1971), a method is required that is convenient to operate relatively simple to construct, and most of all accurate in measurement.

Johnson et al. (1967) have suggested that small (25 x $25 \mathrm{~cm}$ ) metallized polyethylene bags can conveniently replace Douglas bags. However, in their system the dry gas meter (Parkinson-Cowan CD-4) is read manually. Furthermore, the metallized bags are filled manually with a syringe-pumping system. Wilmore (1968) has presented an aliquot system using a vacuum pump to withdraw constant volumes from expired air. He also illustrated manual reading of the dry gas meter and gas temperature. Furthermore, his aliquot bags are the butyle rubber type known to allow rather rapid diffusion of $\mathrm{CO}_{2}$ (Consolazio, 1971). Henry and Katch (1972) have mounted a "contact assembly" to the flow dial of the CD-4 gas meter. The limitation of this system is that due to the positioning of contact bars in the potentiometer, only unit litre points are recorded on the printout. In addition, they make no mention of temperature recording, leading one to assume it is recorded by manual observation.

\section{Basic Design}

The system presently employed by the University of Illinois Physical Fitness Laboratory* meets all the aforementioned prerequisites. The apparatus is, in essence, a combination of those of Johnson et al. (1967), Wilmore (1968), and Henry and Katch (1972), with slight modifications.

\section{Aliquot samples}

Aliquot bags are constructed of metallized polyethylene (Scotchpak film), with the seams sealed by heating. In one corner a polyethylene tube $(3 \mathrm{~mm} \mathrm{ID)}$ is sealed with a one-way stopcock (Tomac, No. 17134-002) attached (Fig. 1). A small vacuum pump is used to evacuate the bags in preparation for sampling; final checking of an evacuated bag is made with a 30-ml

*The author wishes to acknowledge the expertise of Dr. J. Wiley and Mr. R. Geeseman for initial construction of this apparatus.

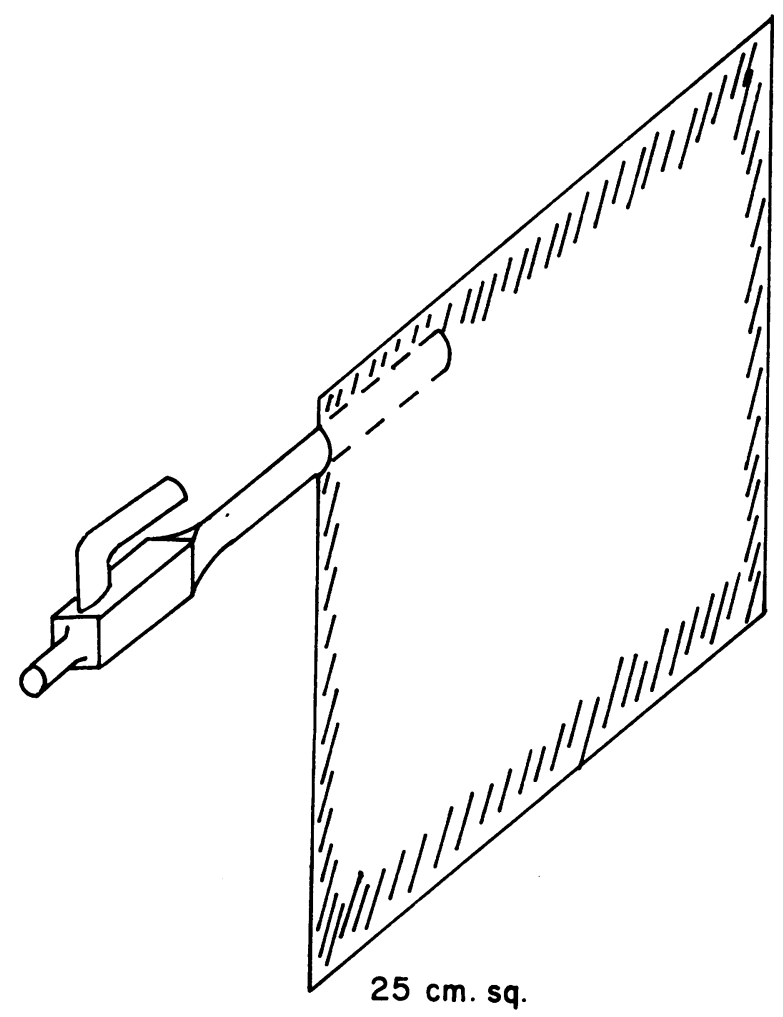

Fig. 1. Metallized polyethylene aliquot bag.

syringe. To evaluate bags for leaks, a sample of air is placed under slight pressure (manual compression) and submerged. Johnson et al. (1967) indicated that the more common causes of failure of bags are puncture holes due to careless handling and breakdown of the seal around the stopcock. In some cases the puncture can be sealed successfully by heat-fusing a small square of Scotchpak over the hole, although Johnson et al. (1967) recommend discarding defective bags.

A copper sleeve $(38 \mathrm{~mm}$ ID $\times 120 \mathrm{~mm}$ long) is inserted in the expired outlet of the CD-4 gas meter, from which surgical rubber tubing $(6 \mathrm{~mm}$ ID) is run to a small vacuum pump (Universal Electric Co., model 2). This pump withdraws a constant flow of gas from the expired side of the meter. Interposed between the pump and the aliquot bag is a flow gauge (Fisher and Porter, model 10A3135M) to regulate the size of the sample taken. Its adjustment allows adequate 15-sec, 30-sec, 1-min, or longer samples. Wilmore (1968) has demonstrated that the constant extraction rate of a 
vacuum pump offers no major limitation to sampling expired gas.

For continuous sampling, a three-way stopcock is modified (Fig. 2) to accept two bags simultaneously.

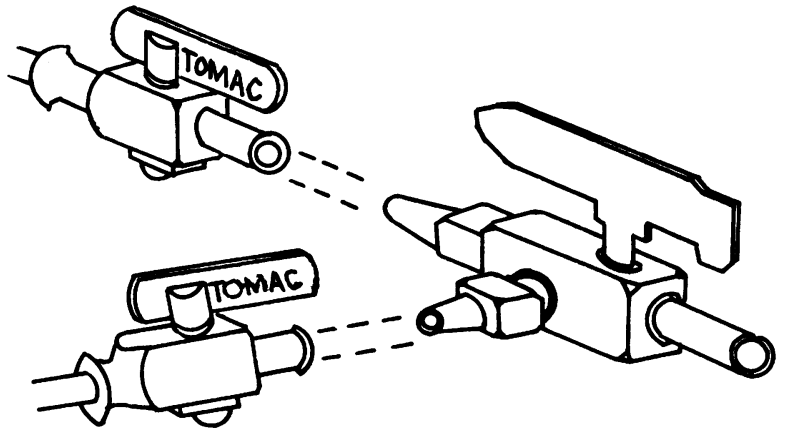

Fig. 2. Modification of three-way stopcock.

\section{Ventilation and temperature recording}

A potentiometer is mounted atop the flow dial of the CD-4 and the output is recorded on an ink recorder (Brush 220). The linearity of the potentiometer and recorder allows exact reading of ventilatory volume accurate to 0.1 litre (Fig. 3). The CD-4 is calibrated with a Tissot respirometer to derive a correction factor to be used in adjusting recorded volumes to actual measurements.

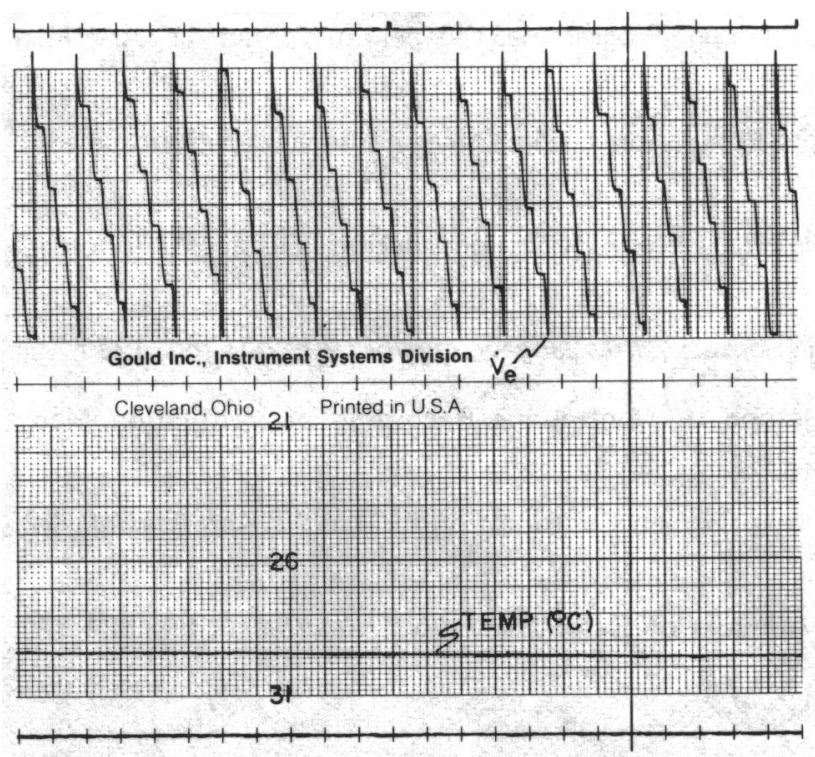

Fig. 3. Ventilation and Temperature record from ink recorder.
A copper sleeve $(38 \mathrm{~mm}$ ID $\times 120 \mathrm{~mm}$ long) is inserted in the inspired inlet of the meter. A thermister is inserted into the inlet to a depth of $10-12 \mathrm{~cm}$. This is connected to a telethermometer (Yellow Springs Instruments, model 46 TUC) which may be read directly or recorded on a second channel of the ink recorder. The latter allows a permanent record of expired volume and gas temperature for later referral (Fig. 3).

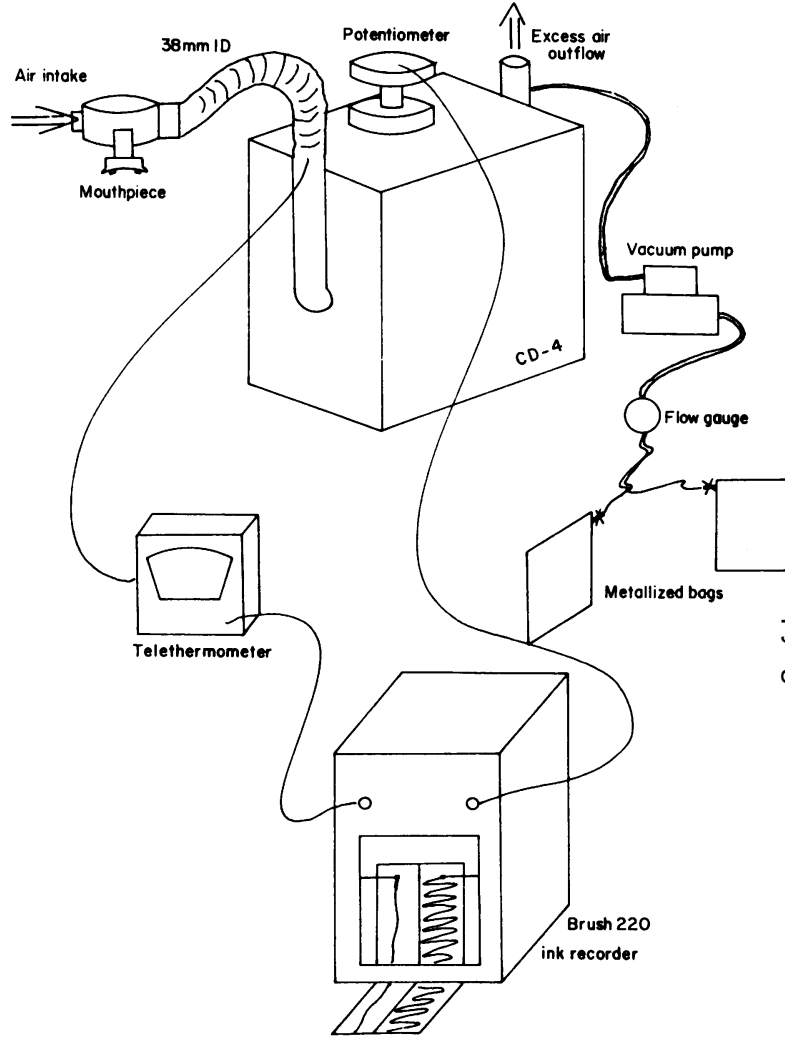

Fig. 4. Schematic representation of gas collection system.

See Fig. 4 for illustration of the entire system. Table 1 lists types and sources of equipment.

\section{Discussion}

Bonen, Gass, and Heyward (1973) recently observed subjects during each of 24 training periods over eight weeks. Five-minute samples of expired gas were taken during a 30-minute work session on a treadmill. By placing the electro-cardiographic recorder near the gas $\stackrel{C}{C}$ collection system, a single operator was able to monitor the entire procedure.

Although probably more costly than the Douglas bag system, the present apparatus offers a simple, accurate 
method of long-term indirect calorimetry monitoring of exercise stress. Due to the very low diffusion capacity of the metallized bags (Johnson et al., 1967), many samples can be taken and stored for later analysis. In addition, continuous load-incremented maximal stress testing can be conducted without fear of surpassing the collection potential of the system. Furthermore, if this equipment is mounted on a wheeled cart, the system is quite mobile.

Table 1

TYPES AND SOURCES OF EQUIPMENT

Type

Metallized polyethylene

One-way stopcock

Tubing

Parkinson-Cowan dry

gas meter

Vacuum pump

Flow gauge

Telethermometer

Ink recorder
Model

Scotchpak No.20

Tomac No.17134-002

$1 \frac{1}{2}$-in. ID

CD-4

No.2

No.10A3135M

No.46 TUC

Brush 220
Source

3M Co., Minneapolis, Minn.

American Hospital Supply, 2020 Ridge Ave., Evanston, III.

W. E. Collins Co., 555 Huntington

Ave., Boston, Mass.

Instrumentation Associates, 17 West 60th St., New York, N.Y.

Universal Electric Co., Owosso, Mich.

Fisher and Porter Co., Warminster, Pa.

Yellow Springs Instrument Co., Yellow Springs, Ohio

Gould Inc., 3631 Perkins Ave., Cleveland, Ohio

\section{REFERENCES}

1. BONEN, A., G. C. GASS, and V. H. HEYWARD. "Adapations of Selected Cardiorespiratory Parameters Monitored Continuously Throughout an Eight Week Treadmill Training Programme." Paper presented at AAHPER Convention, Minneapolis, Minn., 1973.

2. CONSOLAZIO, F. "Energy Expenditure Studies in Military Populations using Kofranyi-Michaelis Respirometers." Am.J.Clin.Nutr., 24: 1431-1437, 1971.

3. COSTILL, D. L., W. F. KAMMER, and A. FISHER. "Fluid Ingestion during Distance Running." Arch.Environ. HIth., 21: 520-525, 1970.

4. COSTILL, D. L. et al. “Determinants of Marathon Running Success." Int.Z.angew.Physiol., 29: 249-254, 1971.

5. HENRY, F. M. and V. L. KATCH. “A Dependable Method of Continuous Recording of Ventilation Meter Output." Res.Quart., 43: 243-246, 1972.

6. JOHNSON, R. E., et al. "A Versatile System for Measuring Oxygen Consumption in Man." J.App.Physiol., 22: 377-379, 1967.

7. WILMORE, J. H. "A Simplified Method for Obtaining Aliquots of Respiratory Air." Res. Quart., 39: 824-828, 1968. 